\title{
Three models of failed athletic contests
}

\author{
Arvi Pakaslahti
}

Department of Philosophy, Political Science and Contemporary History, University of Turku, Turku, Finland arvpak@utu.fi

\begin{abstract}
Arvi Pakaslahti's model of failed athletic contests (the Two Ideals Model) and Mika Hämäläinen's most recent model of failed athletic contests (the Four Items Model) are the two most sophisticated models of failed athletic contests in the philosophy of sport literature. In this paper, I argue that the Two Ideals Model is a more plausible model of failed athletic contests than the Four Items Model. However, I also argue that the Two Ideals Model is an incomplete model of failed athletic contests. I suggest that instead of accepting the Two Ideals Model, it would be better to endorse what I call'the Three Ideals Model'.
\end{abstract}

\section{KEYWORDS}

injustice; athletic skill; athletic superiority; official result; official final ranking

D0I

$10.14712 / 23366052.2018 .6$

(c) 2018 The Author. This is an open-access article distributed under the terms of the Creative Commons Attribution License (http://creativecommons.org/licenses/by/4.0), which permits unrestricted use, distribution, and reproduction in any medium, provided the original author and source are credited. 


\section{INTRODUCTION}

Sometimes a sports contest or its official result(s) may seem fundamentally flawed or defective. In such cases, a sports contest may be called a failed athletic contest. The two most sophisticated models of failed athletic contests in the philosophy of sport literature are Arvi Pakaslahti’s (2016) model and Mika Hämäläinen's (2016) most recent model of failed athletic contests. ${ }^{1}$ For the sake of simplicity and clarity, I will call Pakaslahti's model the Two Ideals Model and Hämäläinen's most recent model the Four Items Model. ${ }^{2}$

The main purpose of this paper is to show that the Four Items Model is not a plausible model of failed athletic contests. I begin by describing the Two Ideals Model and the Four Items Model. Then I argue that the Four Items Model faces three problems which the Two Ideals Model does not face. I conclude that the Two Ideals Model is a more plausible model of failed athletic contests than the Four Items Model. However, I also argue that the Two Ideals Model is an incomplete model of failed athletic contests. I suggest that instead of accepting the Two Ideals Model, it would be better to endorse what I call the Three Ideals Model.

\section{Descriptions of the Two Ideals Model and the Four Items Model}

Let's first have a look at the Two Ideals Model. Pakaslahti writes:

It could be argued that one of the built-in ideals or central goals of each sports contest is that it provides or produces an official result which reflects well the athletic excellence shown by different athletes or teams in that contest. [...] To put it slightly differently, it could be argued that one of the built-in ideals of each sports contest is that it provides an official result which reflects accurately the betterness (i.e. the athletic superiority) of different athletes or teams in that contest. I call this ideal the Athletic Superiority Ideal. [...] Another built-in ideal of sports contests is, I believe, that a contest provides or produces an official result which is just or fair. To put it differently, it seems reasonable to hold that one of the built-in ideals of each sports contest is that it does not lead to injustice in terms of its official result. I call this ideal the Just Results Ideal (Pakaslahti, 2016, pp. 281-282).

Thus, the Two Ideals Model is concerned with realizations of two ideals. The Two Ideals Model also claims that a sports contest was a failed athletic contest if it failed in terms of one or both of the ideals the model includes (see Pakaslahti, 2016, pp. 281-283). A good example of a failed athletic contest which failed in terms of the Athletic Superiority Ideal but which did not fail in terms of the Just Results Ideal is

1 On Hämäläinen's $(2014 ; 2015)$ earlier models of failed athletic contests, see Hämäläinen (2016) and Pakaslahti (2016). On Nicholas Dixon's (2003) model of failed athletic contests, see Hämäläinen (2014; 2015) and Pakaslahti (2016).

2 Pakaslahti (2016) does not give a name to his model of failed athletic contests. Hämäläinen (2016, p. 12) calls his model of failed athletic contests 'the four criteria account' and 'the fourcriterion account'. According to Hämäläinen (2016), the four items which his model consists of are also criteria of betterness or athletic superiority of athletes or teams. I believe that this view is implausible, but I cannot discuss it in this paper. Instead, I will describe Hämäläinen's model in a way that enables me to ignore his view of the criteria of betterness. 
a professional boxing fight in which one of the boxers was better than the other boxer (i.e. in which one of the boxers showed more athletic excellence than the other boxer), ${ }^{3}$ but in which the better boxer was deservedly disqualified in the ninth round due to several rule violations he committed in the ninth round and some of the earlier rounds (see Pakaslahti, 2016, pp. 284-285). A good example of a failed athletic contest which failed in terms of the Just Results Ideal but which did not fail in terms of the Athletic Superiority Ideal is a football match in which one of the teams was better than the other team (i.e. in which one of the teams showed more athletic excellence than the other team), and which the better team officially won due to a serious refereeing error (see Pakaslahti, 2016, pp. 285, 287-288).

It should be noticed, however, that according to the Two Ideals Model, in order for a sports contest not to fail in terms of the Athletic Superiority Ideal, it is enough that its official result reflects the betterness of the athletes or teams accurately in an ordinal sense. For example, if in a football match one of the teams was much better than the other team and officially won the match $1-0$, the official result of the match does not reflect the betterness of the teams accurately in a cardinal sense (i.e. does not reflect accurately which team was better and how much better it was), but does reflect their betterness accurately in an ordinal sense (i.e. reflects accurately which team was better). Thus, the match did not fail in terms of the Athletic Superiority Ideal (Pakaslahti, 2016, p. 282). In a similar fashion, even if the team that officially won the match 1-0 would have deserved to officially win the match by a wider margin, the match did not fail in terms of the Just Results Ideal because the team that deserved to officially win the match in fact officially won the match (Pakaslahti, 2016, pp. 283, 291).

The Four Items Model, on the other hand, consists of four different kinds of items or elements. These items are display of athletic skills, official results, written-rules-based results and ethos-rules-based results (see Hämäläinen, 2016). ${ }^{4}$

Hämäläinen (2015, pp. 18-19; 2016, pp. 9-10) defines athletic skills as those actions or action elements that a sport community values. For example, the football community values, among other things, accurate passes, possessing the ball and powerful shots (see Hämäläinen, 2015, p. 19). On the other hand, in Hämäläinen's (2014) first study of failed athletic contests, Hämäläinen did not define athletic skills as actions or action elements that a sport community values. Instead, Hämäläinen (2014, pp. 290-291) accepted the view that athletic skill consists of physical prowess and relevant mental attributes. However, Hämäläinen $(2016$, p. 9) claims that in his first study of failed athletic contests he referred with athletic skills to those action elements that a sport community values. Thus, I assume that Hämäläinen does not see much of a difference between these two descriptions of athletic skill. For example, it could be asked why the football community values accurate passes? Hämäläinen might answer that the football community values accurate passes because accurate passes are demonstrations of physical prowess.

Pakaslahti (2016, pp. 289-290) thinks that the correct criterion of betterness in sports contests is athletic excellence, with which Pakaslahti (2016, p. 290) refers to those abilities and skills that a sports contest has been designed or is supposed to test.

4 Of these four items, the first two are included also in Hämäläinen's $(2014 ; 2015)$ earlier models of failed athletic contests. 
Of all of the items of the Four Items Model, official results are the most straightforward ones. Official results are simply those results which sports officials and organisations assign or award to contests, athletes and teams. It should be noticed, however, that Hämäläinen talks about official results of athletes and teams, whereas Pakaslahti talks about official results of contests. For example, if a football match between Team $T$ and Team U officially ended 1-0, Hämäläinen would say that Team T's official result is 1 and Team U's official result is 0 (and that Team T's official result is better than Team U's official result), whereas Pakaslahti would say that the official result of the match is 1-0 (see Hämäläinen, 2016; Pakaslahti, 2016).

It should also be noticed that Hämäläinen talks about written-rules-based results and ethos-rules-based results of athletes and teams rather than of contests (see Hämäläinen, 2016). The written-rules-based result of an athlete or team refers to what the official result of an athlete or team in a sports contest should be or should have been from the point of view of the written rules of the sport (see Hämäläinen, 2016, pp. 8-9). Consider a football match between Team V and Team W, which included one refereeing error. The refereeing error took place in the final seconds of the match when the referee incorrectly awarded a goal to Team $V$. The match officially ended 1-0, but it would have officially ended $0-0$ if it had not included the refereeing error. Thus, from the point of view of the written rules of football, Team V's official result should have been 0 , whereas Team W's official result is what it should be from the point of view of the written rules of football. This means that both teams' written-rules-based results are 0 . In other words, the written-rules-based results of Team V and Team W are equally good (or equally bad).

The ethos-rules-based result of an athlete or team refers to what the official result of an athlete or team in a sports contest should be or should have been from the point of view of the ethos rules of the sport (see Hämäläinen, 2016, pp. 8-9). Consider a football match between Team $\mathrm{X}$ and Team $\mathrm{Y}$. The match did not include any refereeing error. In the final seconds of the match, the referee correctly awarded a goal to Team X. However, Team X scored the goal in a way that violated the ethos of football. The match did not include other violations of the ethos of football. The match officially ended 1-0, but it would have officially ended $0-0$ if it had not included the violation of the ethos of football. Thus, from the point of view of the ethos rules of football, Team X's official result should have been 0 , whereas Team Y's official result is what it should be from the point of view of the ethos rules of football. This means that both teams' ethos-rules-based results are 0 . In other words, the ethos-rules-based results of Team $\mathrm{X}$ and Team $\mathrm{Y}$ are equally good (or equally bad).

The Four Items Model is concerned with whether the official result of each of the athletes or teams reflects accurately in an ordinal sense how much athletic skill he/she/ it displayed. The Four Items Model is also concerned with whether the official result of each of the athletes or teams reflects accurately in an ordinal sense how good his/ her/its written-rules-based result and ethos-rules-based result are. ${ }^{5}$ Let's have a look

\footnotetext{
Hämäläinen puts this differently, as according to Hämäläinen (2016), the Four Items Model tests whether there is a conflict between any of the four different kinds of items. For example, consider a sports contest in which Team $\mathrm{E}$ achieved a better written-rules-based result than Team $\mathrm{F}$ but in which they achieved equally good ethos-rules-based results. We could say that
} 
at a football match, in which Team $\mathrm{G}$ achieved a better official result than Team $\mathrm{H}$. If it is also the case that Team G displayed superior athletic skill to Team H (i.e. that Team G displayed more athletic skill than Team $\mathrm{H}$ ), their official results reflect accurately in an ordinal sense how much athletic skill they displayed. If, on the other hand, Team $\mathrm{G}$ did not display superior athletic skill to Team $\mathrm{H}$ (i.e. Team $\mathrm{G}$ displayed less athletic skill than Team $\mathrm{H}$ or Team $\mathrm{G}$ displayed as much athletic skill as Team $\mathrm{H}$ ), their official results do not reflect accurately in an ordinal sense how much athletic skill they displayed. In that case, according to the Four Items Model, the match was a failed athletic contest. Similarly, if Team G did not achieve a better written-rules-based result than Team $\mathrm{H}$ and/or did not achieve a better ethos-rules-based result than Team $\mathrm{H}$, their official results do not reflect accurately in an ordinal sense how good their writtenrules-based results are and/or do not reflect accurately in an ordinal sense how good their ethos-rules-based results are. The Four Items Model claims that in such cases the match was a failed athletic contest (see Hämäläinen, 2016).

\section{Three problems of the Four Items Model}

Pakaslahti constructed an example of a football match in which the ethos of football was violated by two players, and which ended up being a failed athletic contest according to the Two Ideals Model. Pakaslahti used this example for rejecting Hämäläinen's $(2014 ; 2015)$ earlier models of failed athletic contests, as they cannot consider the match a failed athletic contest (see Pakaslahti, 2016, pp. 285, 288-289). ${ }^{6}$ However, Pakaslahti's example can also be used for rejecting the Four Items Model.

The match took place between Team A and Team B. The match was free of refereeing errors and cheating, ${ }^{7}$ and neither team was luckier than the other team (see Pakaslahti, 2016, pp. 285, 289). Pakaslahti (2016, p. 289) claims that Team A was the better team in the match. The rationale is that Team A created legally (i.e. in a way that is permitted by the written rules of football) and fairly (i.e. in a way that is not unfair) more good scoring chances than Team B and shot the ball better than Team B (Team A's shots were more powerful and much less inaccurate than Team B's shots), whereas in all other respects their performances were equally good (see Pakaslahti, 2016, p. 285). However, Team A also created one good scoring chance unfairly (but legally) and scored from it:

the written-rules-based results of that contest are in conflict with the ethos-rules-based results of that contest (see Hämäläinen, 2016, p. 12). However, this conflict implies that the writtenrules-based results and/or the ethos-rules-based results are in conflict with the official results. If Team $\mathrm{E}$ achieved a better official result than Team $\mathrm{F}$, the official results are in conflict with the ethos-rules-based results, whereas if the teams achieved equally good official results, the official results are in conflict with the written-rules-based results. And if Team F achieved a better official result than Team E, the official results are in conflict both with the writtenrules-based results and the ethos-rules-based results.

6 Hämäläinen (2016) responded to Pakaslahti's criticism by developing his second model of failed athletic contests into the Four Items Model. Pakaslahti (2016, pp. 289-290) also provided another argument against Hämäläinen's earlier models of failed athletic contests, which Hämäläinen (2016, p. 10), however, rejected.

7 Cheating is understood here so that a necessary condition of cheating in a sports contest is that one breaks a written rule. 
In the final moments of the match, Team B is on the attack and in possession of the ball, when a player (Player P) of Team A sprains his ankle and falls to the ground in pain. A player of Team B kicks the ball out of play, so the injured player can be treated, even though this deprives Team B of the advantage. When play is restarted a player (Player Q) of Team A takes the throw-in but does not return the ball to Team B. Instead, he intentionally throws the ball to one of the attackers (Player R) of Team A, who is unmarked and in a very good position to break through the defence of Team B. Player R also does not return the ball to Team B. Instead, he breaks through, runs with the ball, feints the goalkeeper and scores. The match ends 1-0 (Pakaslahti, 2016, p. 289).

Although Team A was the better team in the match, it seems that Team A did not deserve to officially win the match because it scored its goal unfairly. The way in which Team A scored was unfair because the goal it scored was based on a violation of an important convention (or ethos rule) of football. This violation led to an unjust official result (see Pakaslahti, 2016, p. 289). It seems to me clear that the official result of the match is so unjust that the match should be considered a failed athletic contest. Thus, the right answer to the question whether the match was a failed athletic contest seems to be 'yes'. The Two Ideals Model clearly gives this answer. But can the Four Items Model conclude that the match was a failed athletic contest?

Team A achieved a better official result, as Team A's official result is 1 and Team B's official result is 0 . It seems also clear that according to the Four Items Model, Team A displayed superior athletic skill, because the football community values the creation of good scoring chances and because how much the football community values a shot is determined partly by how accurate and/or powerful it was. Team A also achieved a better written-rules-based result. Since the official results of both teams are what they should be from the point of view of the written rules of football, Team A's written-rules-based result is 1 and Team B's written-rules-based result is 0 .

We can now see that if it is the case that Team A did not achieve a better ethosrules-based result, the match was a failed athletic contest according to the Four Items Model, and that if it is the case that Team A achieved a better ethos-rules-based result, the match was not a failed athletic contest according to the Four Items Model. Hämäläinen (2016, pp. 9, 12) claims that Team A’s ethos-rules-based result is 0. Saying that Team A's ethos-rules-based result is 0 means that Team A's official result should have been 0 from the point of view of the ethos rules of football. Thus, Hämäläinen assumes that Team A would not have been awarded a goal (i.e. Team A would not have officially scored) in the final moments of the match if Player Q and Player R had not violated the ethos of football. This assumption implies that Team A's ethos-rulesbased result is not better than Team B's ethos-rules-based result, which means that either both teams' ethos-rules-based results are equally good (i.e. neither team would not have been awarded a goal in the final moments of the match if Player Q and Player $\mathrm{R}$ had not violated the ethos of football) or Team B's ethos-rules-based result is better (i.e. Team A would not have been awarded a goal in the final moments of the match but Team B would have been awarded a goal in the final moments of the match if Player Q and Player R had not violated the ethos of football).

The problem is that it could not be confirmed that Team A would not have been awarded a goal in the final moments of the match if Player Q and Player R had not vio- 
lated the ethos of football. Perhaps Team A would have officially won the match even if Player Q and Player R had not violated the ethos of football. It is possible (although very unlikely) that if Player $Q$ had thrown the ball to one of the players of Team B, Team $B$ would have lost the possession of the ball a few seconds later and Player $\mathrm{R}$ (or some other player of Team A) would have broken through and scored (without violating the ethos of football). But no one could ever discover whether or not that would have happened. Thus, the epistemic problem is that it would be impossible to discover what the ethos-rules-based result of Team A is. This implies that from the point of view of the Four Items Model, it is not clear that the match was a failed athletic contest. In other words, the Four Items Model leaves it open whether the match was a failed athletic contest. But since the official result of the match is clearly very unjust, it seems to me clear that the match was a failed athletic contest.

If it could be discovered what the ethos-rules-based results of Team A and Team $\mathrm{B}$ are and it were discovered that they are 1 and 0 , it might make sense to say that the actual official result of the match, $1-0$, is not unjust. In other words, if it could be discovered that the match would have officially ended 1-0 even if Player $\mathrm{Q}$ and Player R had not violated the ethos of football in the final moments of the match, it might make sense to say that the actual official result of the match is not unjust. But it is clear that no one could ever discover the ethos-rules-based results of Team A and Team B. Thus, the possibility that Team A would not have officially won the match if Player Q and Player R had not violated the ethos of football and the impossibility of discovering whether Team A would have officially won the match if Player Q and Player R had not violated the ethos of football allow us to conclude that the actual official result of the match is unjust.

So the first problem of the Four Items Model is related to the achievement of a better ethos-rules-based result. The second problem of the Four Items Model concerns the achievement of a better written-rules-based result. This problem can be illustrated with the following football match between Team $\mathrm{C}$ and Team $\mathrm{D}$. In this match no player violated the ethos of football. However, the match included one refereeing error. The error took place on the 75th minute when one of the players of Team C shot the ball towards Team D's goal. The shot was quite powerful and the ball crossed the goal line partly before the goalkeeper managed to save the shot. However, the referee and assistant referee believed that the ball crossed the goal line completely. Thus, the referee awarded a goal to Team $\mathrm{C}$. The match officially ended $1-0$. Team $\mathrm{C}$ created six or seven good scoring chances in the match, whereas Team D had only two or three good chances to score a goal. On the other hand, despite having many good scoring chances in the match, Team C had just one shot on target (i.e. the shot on the 75th minute). However, Team D did not have any shot on target. Moreover, some of Team C's shots which missed the target were powerful and narrowly wide, whereas none of Team D's shots was powerful and all of them missed the target by three or four metres.

It seems to me clear that the official result of the match is so unjust that the match should be considered a failed athletic contest. Thus, the right answer to the question whether the match was a failed athletic contest seems to be 'yes'. The Two Ideals Model clearly gives this answer. The Four Items Model, however, cannot conclude that the match was a failed athletic contest. The Four Items Model says that the match was a failed athletic contest if it is the case that Team C did not achieve a better written- 
rules-based result than Team D. But it is possible that Team C's written-rules-based result is better than Team D's written-rules-based result, as it is possible that Team C would have been correctly awarded a goal later in the match (e.g. on the 79th or 87th minute) if it had not been incorrectly awarded a goal on the 75th minute. However, it could never be discovered whether or not that would have happened, because no one could find out how the match would have developed if Team $\mathrm{C}$ had not been incorrectly awarded a goal on the 75th minute. Thus, the epistemic problem is that it would be impossible to discover what the written-rules-based result of Team C is. This implies that the Four Items Model leaves it open whether the match was a failed athletic contest. In other words, the Four Items Model cannot claim that the match was a failed athletic contest. It can only claim that the match was a failed athletic contest if Team C's written-rules-based result is not better than Team D's written-rules-based result. But since the official result of the match is clearly very unjust, it seems to me clear that the match was a failed athletic contest.

If it could be discovered what the written-rules-based results of Team C and Team $\mathrm{D}$ are and it would be discovered that they are 1 and 0 , it might make sense to say that the actual official result of the match, 1-0, is not unjust. In other words, if it could be discovered that the match would have officially ended $1-0$ even if the refereeing error had not occurred, it might make sense to say that the actual official result of the match is not unjust. But it is clear that no one could ever discover the written-rules-based results of Team C and Team D. Thus, the possibility that Team C would not have officially won the match if the refereeing error had not occurred and the impossibility of discovering whether Team $\mathrm{C}$ would have officially won the match if the refereeing error had not occurred allow us to conclude that the actual official result of the match is unjust.

The third problem of the Four Items Model is terminological. This problem may be less serious than the previous problems, but I think it is worth discussing. It can be illustrated with a professional boxing fight between Boxer $\mathrm{O}$ and Boxer $\mathrm{P}$, which took place in the heavyweight division. Boxer $\mathrm{O}$ is a big heavyweight who is famous for his very long reach and extremely powerful punches. Boxer $\mathrm{P}$, on the other hand, is a very small heavyweight who used to fight in the cruiserweight division. He also has a short reach for the heavyweight division. Boxer $\mathrm{P}$ is, however, a very technical boxer and is famous for his footwork, head movement and hand speed. By utilizing his huge reach advantage, Boxer $\mathrm{O}$ ended up landing slightly more punches in the fight. Boxer $\mathrm{O}$ also landed the hardest punches of the fight, but he was unable to knock down Boxer P or truly hurt him. Boxer P, on the other hand, demonstrated superior footwork, head movement and hand speed. Due to his much faster hands and much better footwork and head movement, Boxer $\mathrm{P}$ was able to make the fight very close. The fight was, however, very easy to score, as Boxer O landed much more punches in seven rounds and Boxer $\mathrm{P}$ landed much more punches in five rounds. Moreover, in those rounds in which Boxer O landed more punches, he also landed the hardest punches of the fight, whereas in those rounds in which Boxer $\mathrm{P}$ landed more punches, Boxer $\mathrm{O}$ did not land any hard punches. All three judges scored the fight 115-113 for Boxer O.

On the basis of the description of the fight and the fighters, it makes sense to say that Boxer P demonstrated superior athletic skill, as he was only narrowly beaten by an extremely powerful boxer who had huge size and reach advantages. However, since Boxer $\mathrm{O}$ landed more punches in the majority of the rounds and the fight as a whole, 
and since Boxer $\mathrm{O}$ also landed the most powerful punches of the fight in the rounds in which he landed more punches than Boxer $\mathrm{P}$, it seems to me clear that Boxer O showed more athletic excellence, or demonstrated superior athletic abilities, as a heavyweight boxer.

It is also clear that the boxing community values punches which land (except when they are not in accordance with the written or ethos rules of boxing). Moreover, the boxing community values such punches even more when they are powerful. These considerations suggest that understanding the term 'athletic skill' as Hämäläinen does implies the conclusion that Boxer O demonstrated superior athletic skill. However, it seems to me that with athletic skill Hämäläinen refers to a property that he should have called 'athletic excellence' or 'athletic ability'. Thus, I believe that Hämäläinen uses a wrong term when he uses the term 'athletic skill'. I think that instead of using the term 'athletic skill', Hämäläinen should have used the term 'athletic excellence' or the term 'athletic ability'.

\section{CONCLUSION}

I have shown that the Four Items Model faces three problems which the Two Ideals Model does not face. Certainly, the third problem of the Four Items Model is trivial in the sense that it is merely terminological and could be fixed easily by replacing the term 'athletic skill' with a better term. The other two problems, on the other hand, are more fundamental, because they are related to some of the concepts (rather than to some of the terms) the Four Items Model includes.

Since I cannot think of the Four Items Model having any advantage over the Two Ideals Model, I conclude that the Two Ideals Model is a more plausible model of failed athletic contests. However, even if the Two Ideals Model is a more plausible model of failed athletic contests, it seems to me that it is an incomplete model of failed athletic contests. ${ }^{8}$ I believe that instead of accepting the Two Ideals Model, it would be better to endorse a model which includes the Athletic Superiority Ideal, the Just Results Ideal and the Official Rankings Ideal. I call this model 'the Three Ideals Model'. According to the Three Ideals Model, all these three ideals should be considered built-in ideals of each sports contest. Related to this, the Three Ideals Model also claims that a sports contest was a failed athletic contest if it failed in terms of any of these ideals.

The Official Rankings Ideal is that a sports contest ends up providing official final rankings. For example, consider a ski jumping contest in which fifty ski jumpers were scheduled to compete, but which was cancelled after twenty jumps due to dangerous weather conditions. Since the contest did not end up providing official final rankings, it failed in terms of the Official Rankings Ideal and was thus a failed athletic contest according to the Three Ideals Model. Consider also a professional boxing fight, in which an accidental headbutt in the second round opened a huge cut above the right eye of the boxer who was headbutted, and in which the referee stopped the fight on the ring doctor's recommendation after the third round and ruled the fight a no-contest. The referee ruled the fight a no-contest because the written rules of the fight

8 Pakaslahti (2016, p. 290) in fact notes that his account of failed athletic contests may be incomplete. 
required him to make such a ruling. A no-contest as an official result of a professional boxing fight indicates that no one officially won the fight, that no one officially lost the fight, and that the fight was also not officially a draw. Thus, if a professional boxing fight ended up being officially a no-contest, it implies that neither boxer achieved a better official final ranking and that the fighters also did not achieve equally good official final rankings. In other words, if a professional boxing fight ended up being officially a no-contest, it implies that the fight did not end up providing official final rankings. This means that in the previous example, the fight failed in terms of the Official Rankings Ideal and was thus a failed athletic contest according to the Three Ideals Model. ${ }^{9}$

But why should the Official Rankings Ideal be considered one of the built-in ideals of each sports contest? Sigmund Loland writes:

After the last round, a boxer's points are counted and compared with those of his opponent to rank the two boxers accordingly. After all marathon runners have crossed the finishing line, we rank them according to time taken for the complete distance. [...] it is possible to formulate a general goal that characterizes sport competitions as such: the goal of sport competitions is to measure, compare and rank two or more competitors according to athletic performance. This goal seems to be common to all sports [...] It defines sport's characteristic social structure, and I shall therefore call it the structural goal of sport competitions (Loland, 2002, pp. 9-10).

So, if ranking competitors (and teams) is part of the goal that characterizes sports contests and defines sport's characteristic social structure, it makes sense to consider the Official Rankings Ideal one of the built-in ideals of each sports contest. It should be noticed, however, that measuring and comparing are merely means for ranking competitors. Loland (2002, p. 9) in fact notes that 'measuring and comparing performances leads to a final ranking of competitors according to performance'. Thus, although it makes sense to say that measuring, comparing and ranking competitors define sport's characteristic social structure, I believe that measuring and comparing competitors are not part of the structural goal of sports contests; it seems to me that the structural goal of sports contests is to rank competitors rather than to measure, compare and rank competitors.

\section{REFERENCES}

Dixon, N. (2003). On winning and athletic superiority. In: Boxill, J. (Ed.), Sports Ethics: An Anthology (pp. 116-129). Malden: Blackwell Publishing.

Hämäläinen, M. (2014). Three standards of athletic superiority. Journal of the Philosophy of Sport, 41(3), 289-302.

9 It should be noted that in the fight of the previous example any other official result than a nocontest would have been a very unjust official result. For example, if the referee would have mistakenly believed that the cut had been caused by a punch and he would have therefore awarded a technical knockout victory to the boxer who accidentally headbutted the other boxer, the official result would have been very unjust. Thus, the fight did not end up failing in terms of the Just Results Ideal but would have failed in terms of the Just Results Ideal if it had not been ruled a no-contest (in which case it would not have failed in terms of the Official Rankings Ideal). 
Hämäläinen, M. (2015). The concept of betterness and sport competitions. Ph.D. diss. University of Turku.

Hämäläinen, M. (2016). Who was the better athlete? Which was the better team? Acta Universitatis Carolinae. Kinanthropologica, 52(1), 5-14.

Loland, S. (2002). Fair Play in Sport. London: Routledge.

Pakaslahti, A. (2016). Betterness, injustice and failed athletic contests. Journal of the Philosophy of Sport, 43(2), 281-293. 